- Ronald A. Wells, Tranquillity Enterprises, s.p., Abingdon, VA Harrison H. Schmitt, Dept. Eng. Physics, Univ. Wisc.-Madison, Albuquerque, NM

Software used: Adobe Lightroom, Corel Photo-Paint

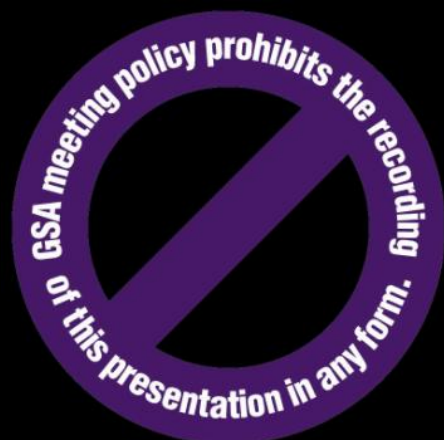

All color-balanced photos copyright $(\odot) 2018$ by Tranquillity Enterprises, s.p. U.S. Copyright Office i.d. 1-7009355371 
Slide \#1 (Title Slide; also see "Endnote", final slide):

Several papers today have mentioned the "Legacy of Apollo". I want to address a specific legacy that has been grossly distorted for almost a half century. Let me begin by reading the first sentence of the abstract: "Seven photographs of a trench dug across an orange tinted, oval area on the rim of Shorty Crater at Station 4 by Apollo 17 Astronaut Harrison H. Schmitt documented one of the most remarkable discoveries of the Apollo program." 


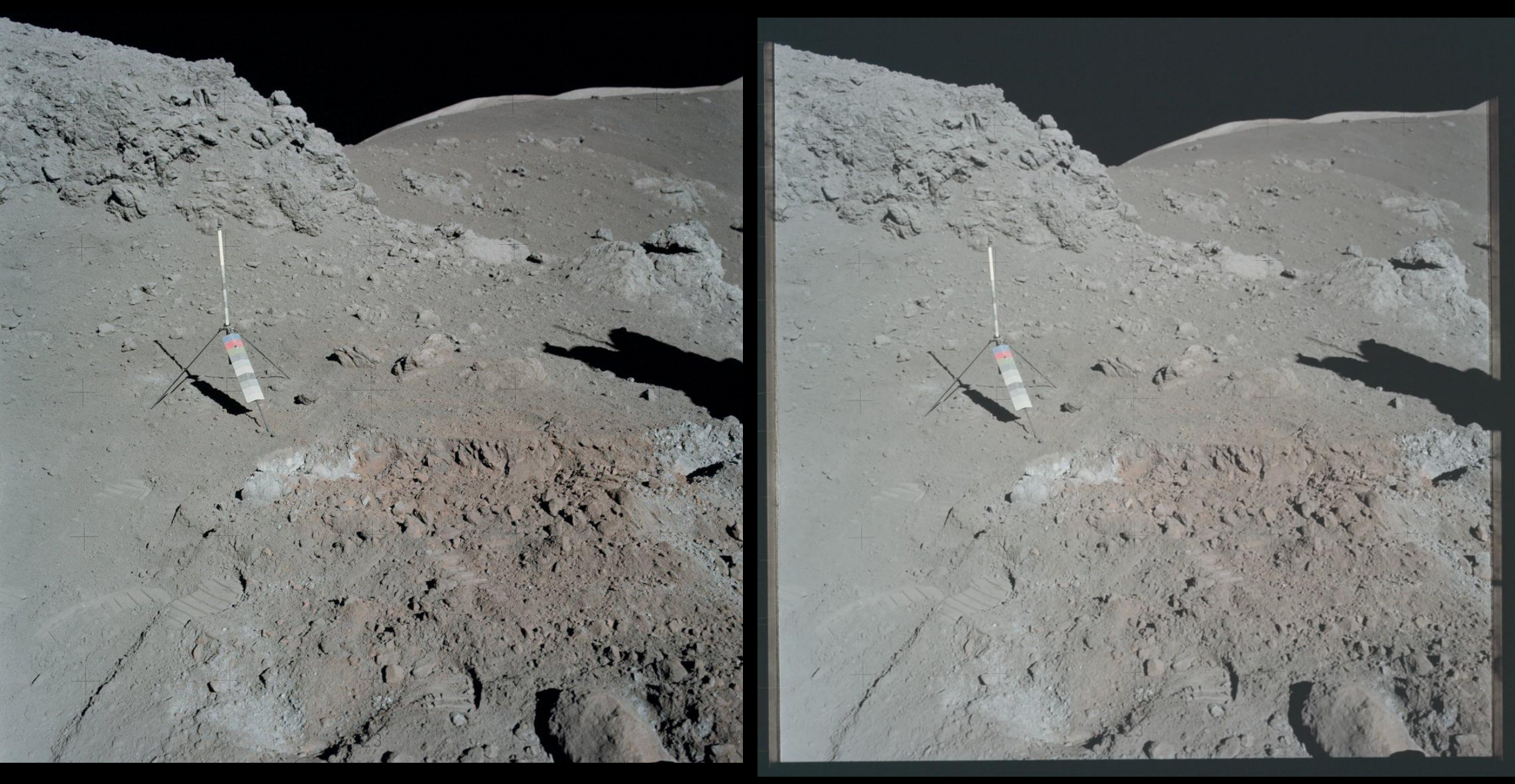




\section{Slide \#3:}

But for decades after the photos of the trench were returned to the Earth, except for a few die-hard geochemists and geologists who examined the colored glass beads, people found it hard to get excited because the printed photographs (e.g., see Apollo 17 Preliminary Science Report, NASA SP-330, 1973) and later digital scans showed mostly a muddy view like that at left, which has been available in the Apollo Lunar Surface Journal for 15 years. Or even like the one on the right, available on Kipp Teague's Project Apollo Archive website since 2015, the original untouched scan direct from JSC. (NASA photo AS17-137-20990). 


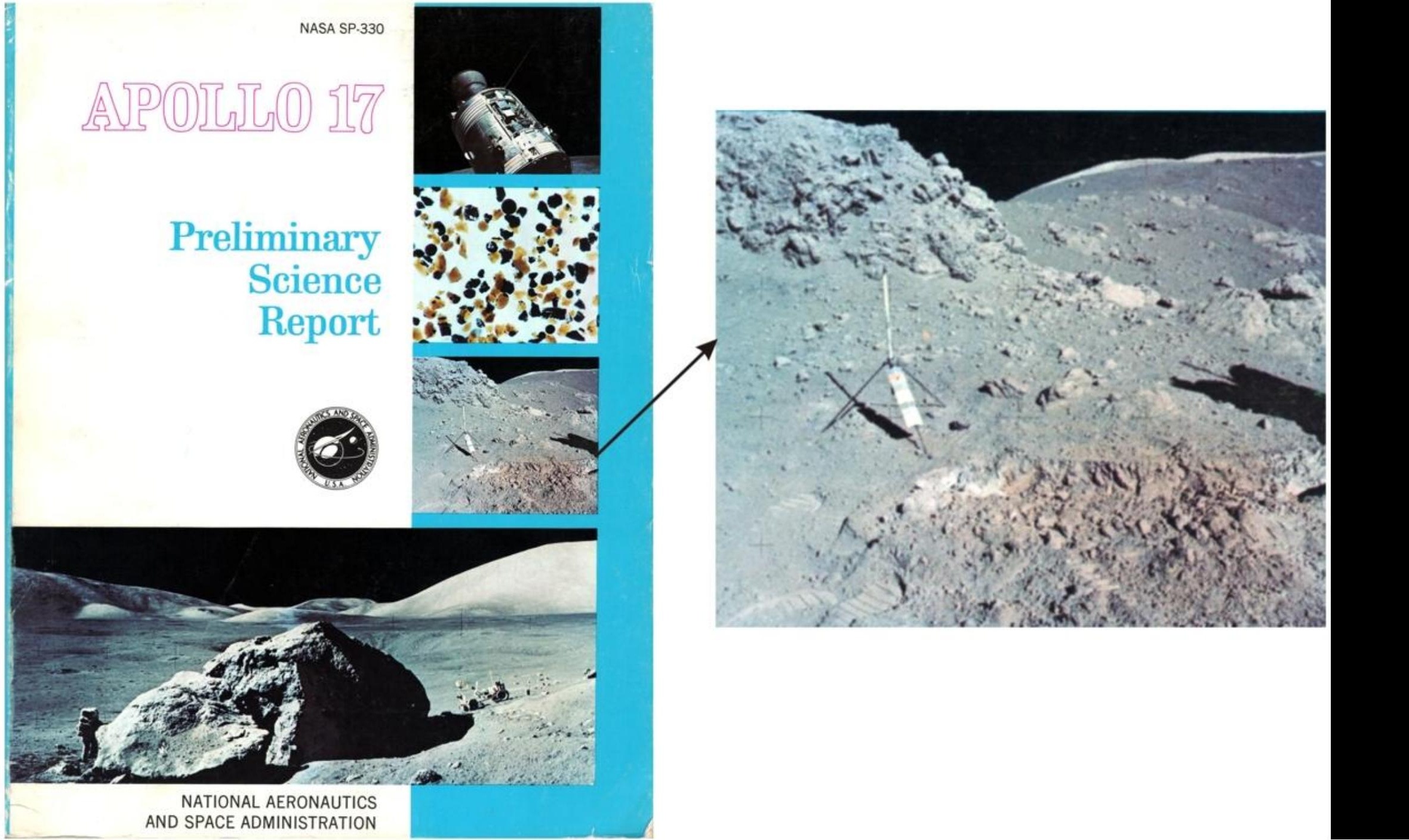


Slide \#5:

The front cover of the Apollo 17 Preliminary Science Report dated 1973 showing the printed image of AS17-137-20990. An enlargement of it is shown at right. The colors in the trench have not been improved upon thirty years later by the two versions of the JSC digital scan shown in the previous slide! 

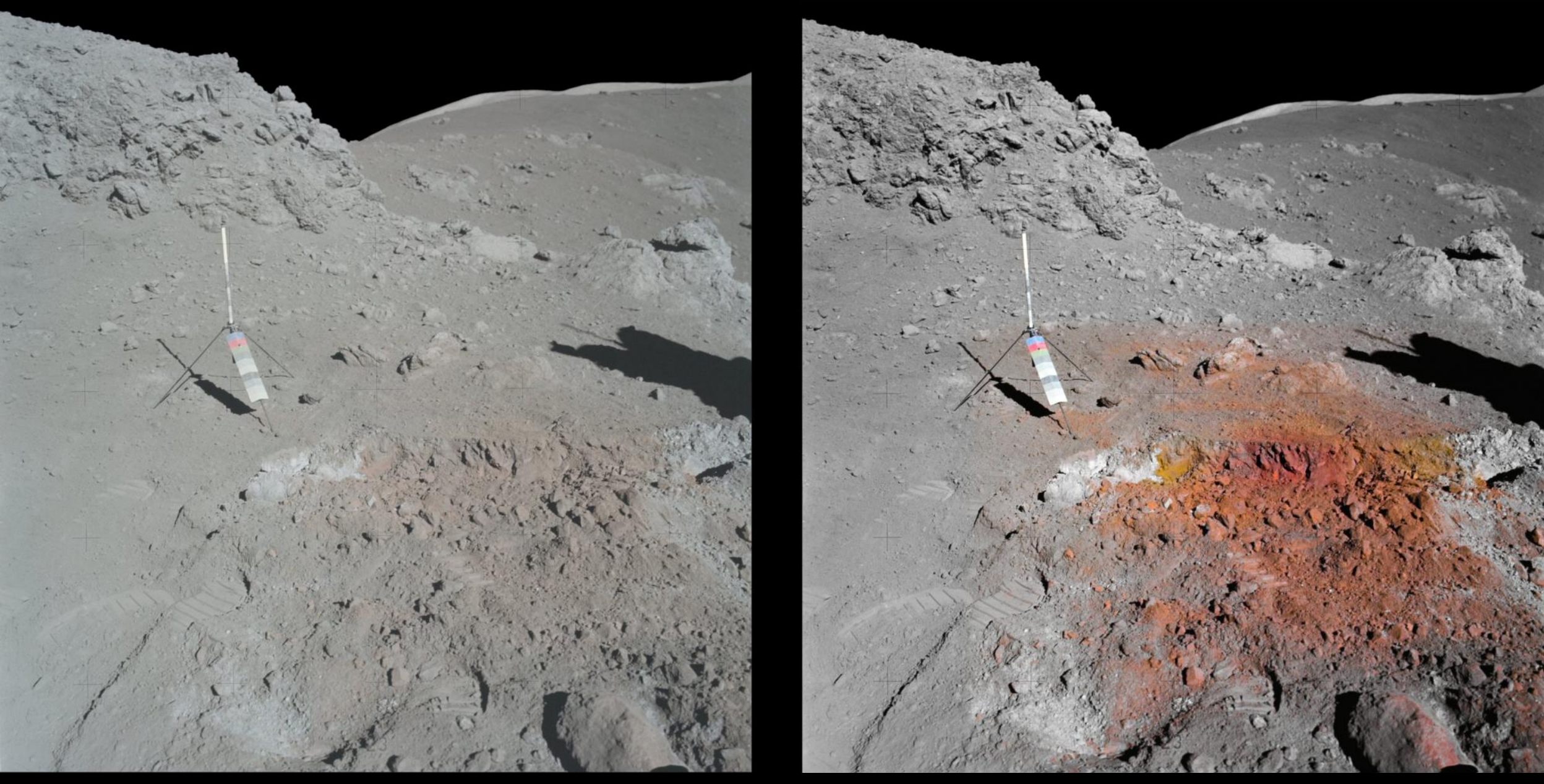


\section{Slide \#7:}

In actual fact, what Jack saw after trenching, and he later confirmed by inspecting the prime film in Houston with a 10x jeweler's loop, is shown at right. This color balanced version was made, not by adding colors, but rather by adjusting colors already present in the digital data. I don't have the time to run through the various steps in Adobe Lightroom or Corel Photo-Paint to explain how this was done. But briefly one begins by equalizing or balancing the color contrasts in the image. Then it is split into red, orange, and yellow color channels. The color in each is saturated to $100 \%$. And then one begins to dial back the amount of color, making combinations that Jack inspected. It took 8 iterations before Jack was satisfied that this represented what he saw. (color adjusted derivative photo copyright (C) 2018 by Tranquillity Enterprises, s.p.) 


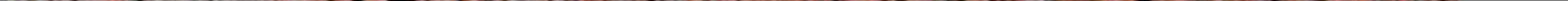




\section{Slide \#9:}

This enlargement of the trench area demonstrates what is meant by red, orange, and yellow areas, and the transitions between them. I found it most interesting that the color changed to yellow at each end of the trench. The only really "orange" part that first caught Jack's attention when he came around the end of the rover is the part on top of the surface between the gnomon and his shadow at right. (derivative photo copyright (C) 2018 by Tranquillity Enterprises, s.p.) 


\section{Southwest}

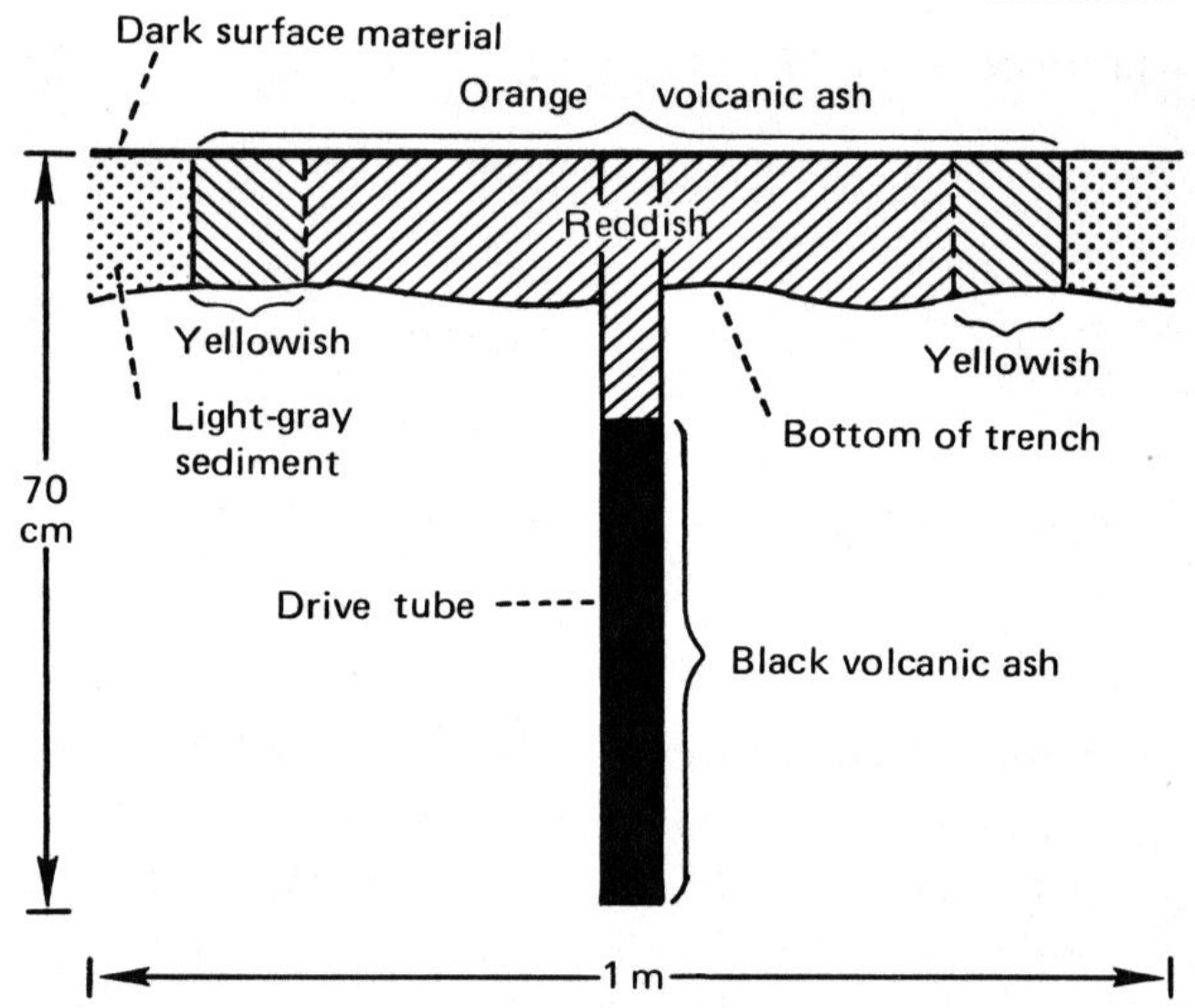

FIGURE 122.-Schematic cross section showing materials in trench and double drive tube on rim crest of Shorty crater (modified from Muehlberger and others, 1973). 


\section{Slide \#11:}

In fact, this color variation was reported at the time. I wanted to find out the distribution of the different colored glass beads in the returned samples, so I looked it up and found this figure in USGS Professional Paper 1080, published in 1981 by Wolfe et al.; but based on a similar diagram published in 1973 within a year or so of the end of the Apollo 17 mission. Red in the center of the trench; yellow on either end, transitioning to light gray sediment; and orange on the top. 


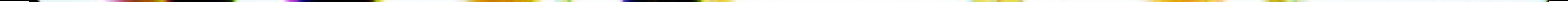




\section{Slide \#13:}

And, of course, a photomicrograph of part of the core sample shows shards, spheres, and spheroids of orange, yellow, orangish-red, and black glass. (NASA photo S73-15171). 

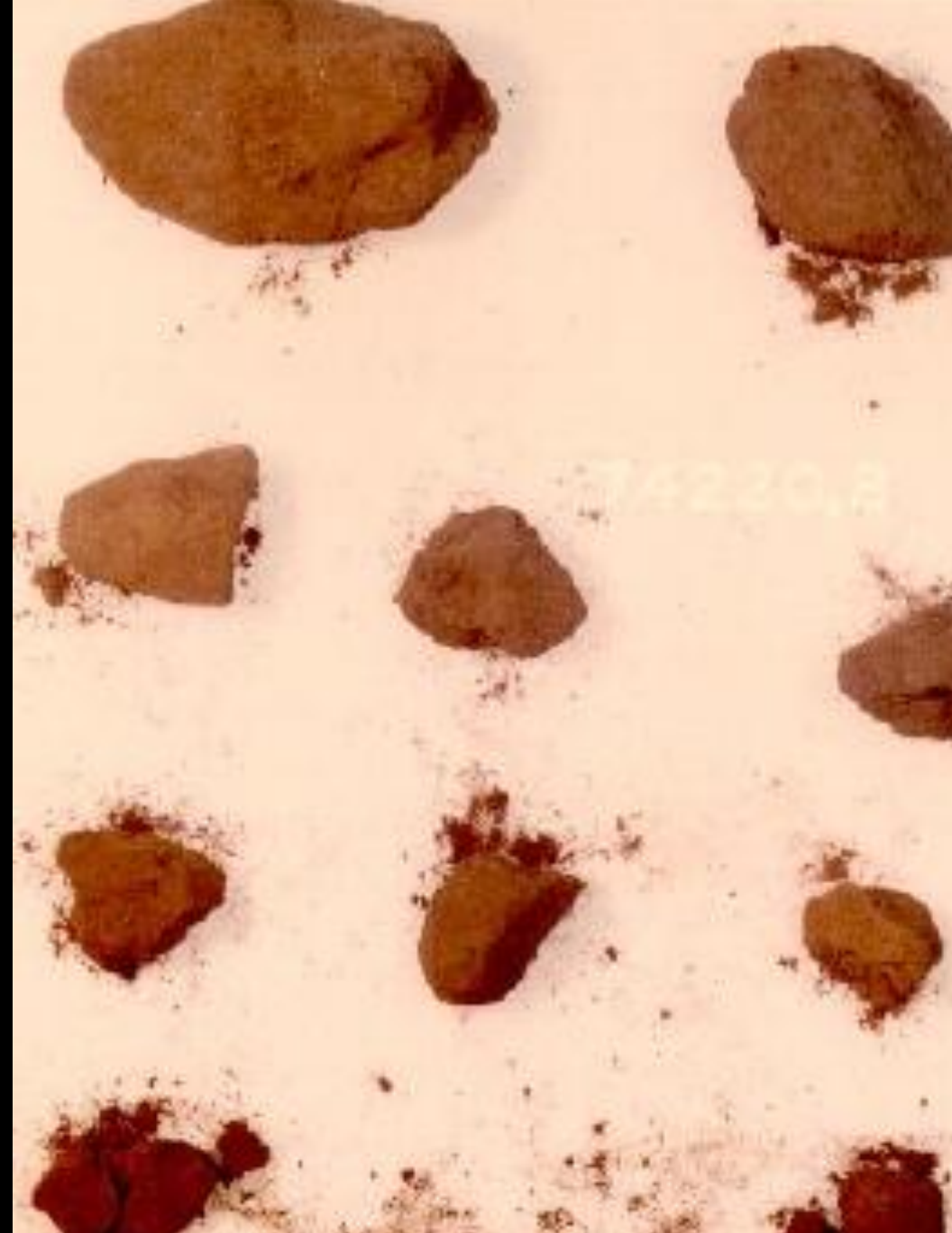

ac $y^{2}$
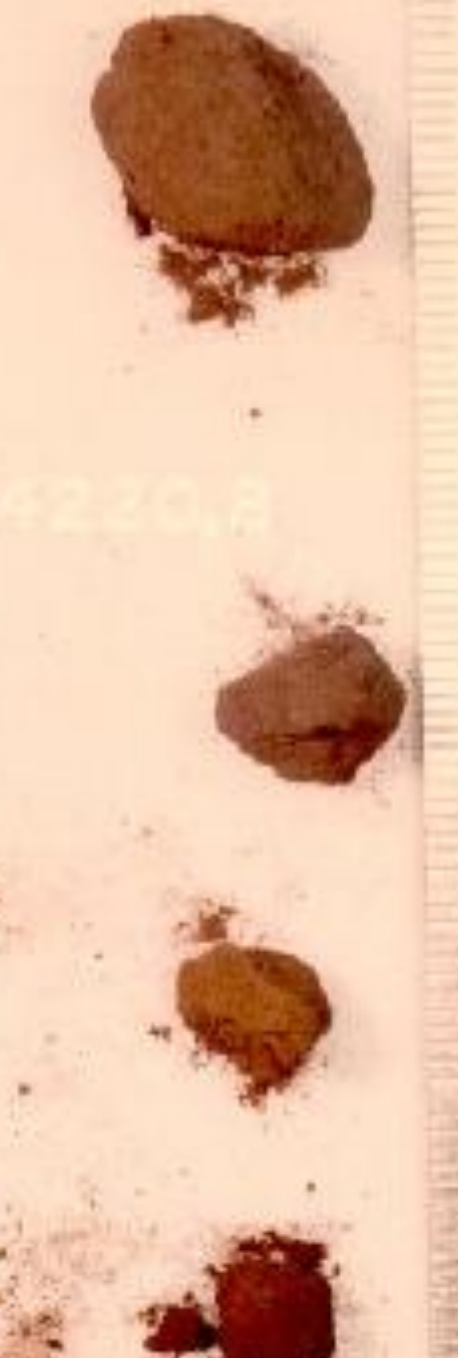


\section{Slide \#15:}

Red (rows 1, 3, and 4) and reddish-brown (row 2) clods of soil taken from the bottom central area of the trench. Compare with slide \#9. The color matches are in excellent agreement. The color-balancing of AS17-137-20990, however, was completed before this photo of the soil clods had been inspected. (C. Meyer, Lunar Sample Compendium, Apollo 17, sample no. 74220,8; Fig. 20, NASA photo S75-34259) 


\section{Slide \#17:}

So now I want to show the other 6 photos that Gene Cernan took of the trench. At left is AS17137-20984, the first of the 7 and at the largest phase angle, i.e., angle between the direction of the sun and the direction of the camera. Here the orange top layer that caught Jack's attention is easier to see. At right is AS17-137-20985. (derivative photos copyright (C) 2018 by Tranquillity Enterprises, s.p.) 

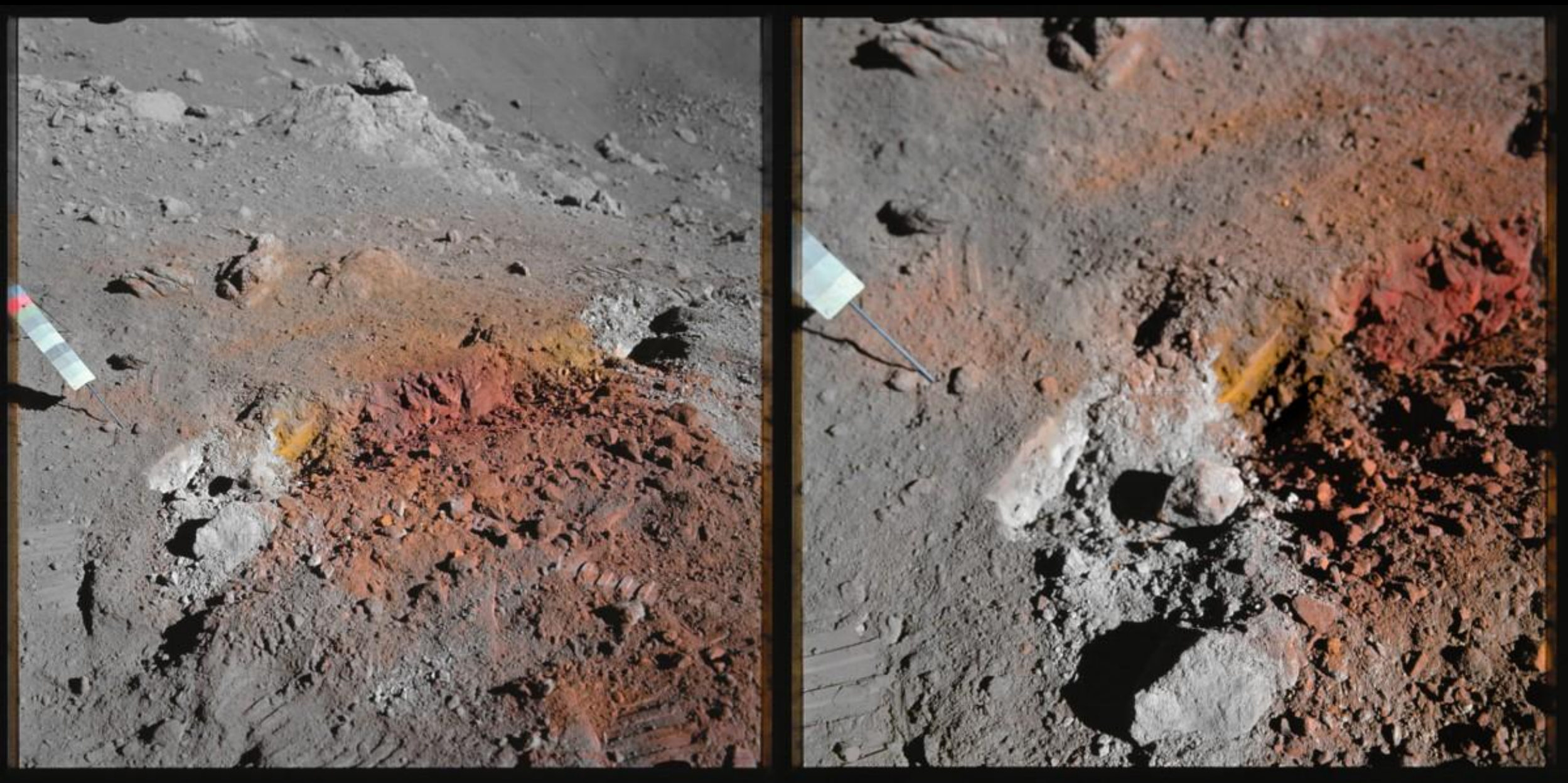


\section{Slide \#19:}

At left is AS17-137-20986. And at right, AS17-137-20987. This latter one and the next 2 are close-ups of the central and left part of the trench. (derivative photos copyright (C) 2018 by Tranquillity Enterprises, s.p.) 

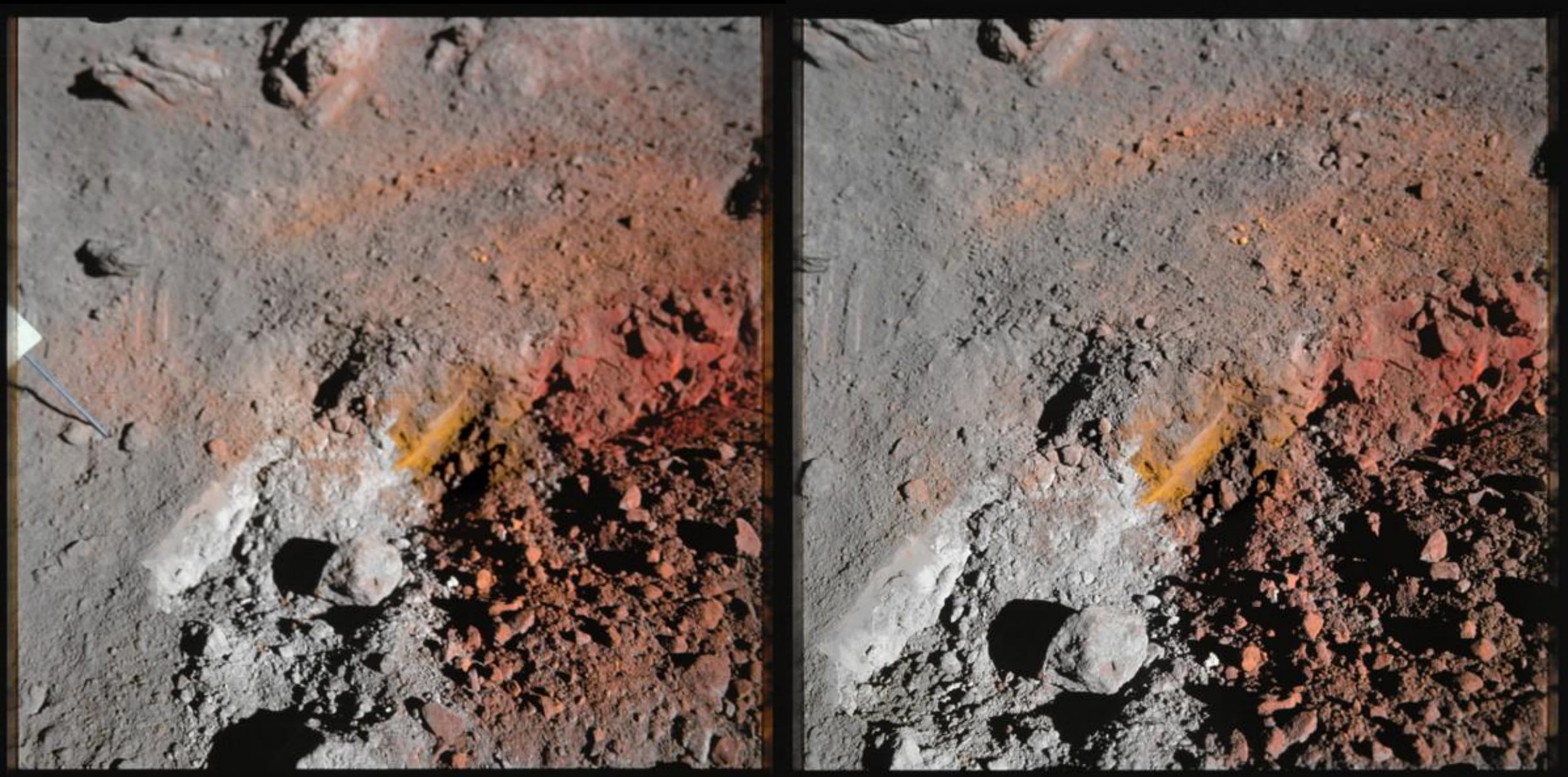


\section{Slide \#21:}

At left is AS17-137-20988. And at right, AS17-137-20989. This latter is the next to the last one of the 7. We looked at the last one, AS17-137-20990, first. Because it was almost directly facing the trench with the smallest phase angle, it served as the model for the detailed color balancing parameters, used for all the others. (derivative photos copyright (c) 2018 by Tranquillity Enterprises, s.p.) 


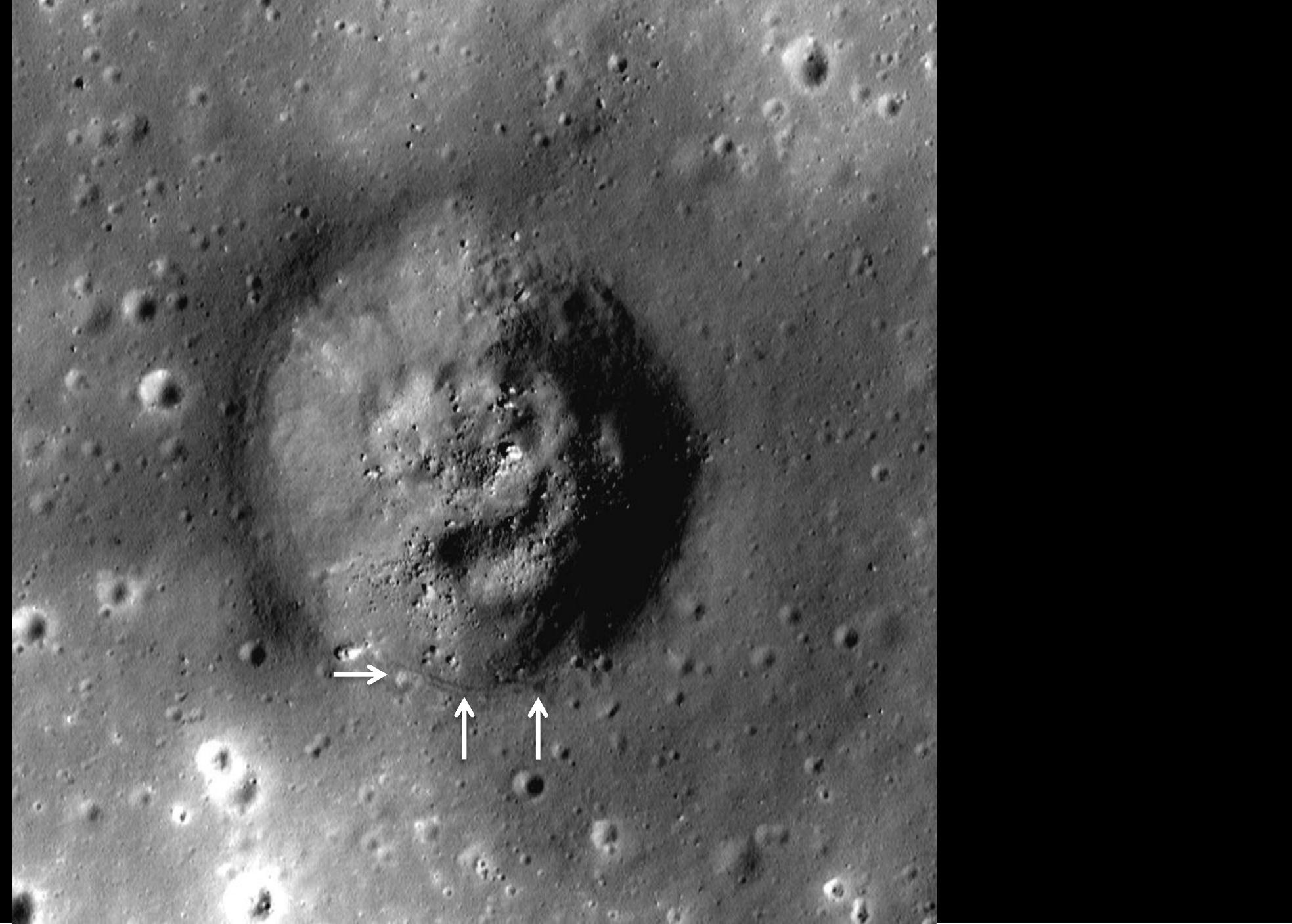




\section{Slide \#23:}

This LRO NAC overhead shows some of the details. The left horizontal arrow points to the light-colored trench. The dark half-circle beneath it are the tracks made by Gene as he stepped back \& forth taking pictures of the trench. The twin tracks marked by the vertical arrow are tracks left by Cernan when he walked out to where he took 37 photos as panoramas of the interior walls of Shorty Crater; and the rightmost vertical arrow denotes the spot where he made his turns clockwise, then counter-clockwise while taking the panorama photos which we shall now look at. 


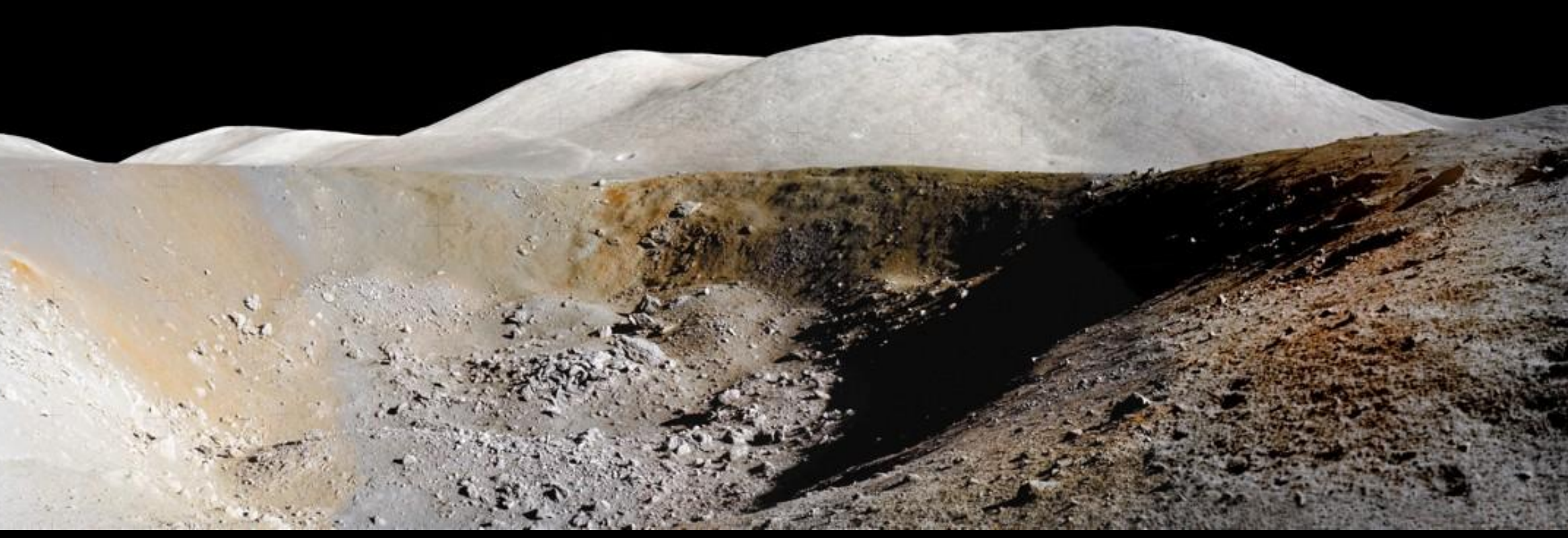


Slide \#25:

While at that spot, Cernan took an additional 37 photos in two and a fraction panoramic turns. Here are 7 of them showing the whole of Shorty Crater in color. AS17-137-21005,-00,-01,-02,$03,-04,-24$ in that order, left-to-right. We should also take a look at several of the individual photos because of the very interesting features in each. (derivative photo copyright (C) 2018 by Tranquillity Enterprises, s.p.) 


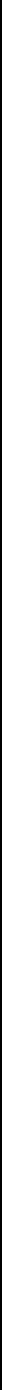




\section{Slide \#27:}

Starting left-to-right, AS 17-137-21005, shows a bright red streak amidst broader orange material that has slumped down the wall to the crater floor. An enlargement of the red streak is shown at right. Note the orange surface area on the rim at the bottom right of the left photo- that is how Jack saw the surface before he made the trench, which is located just off the left of the photo at upper left. (derivative photos copyright (c) 2018 by Tranquillity Enterprises, s.p.) 

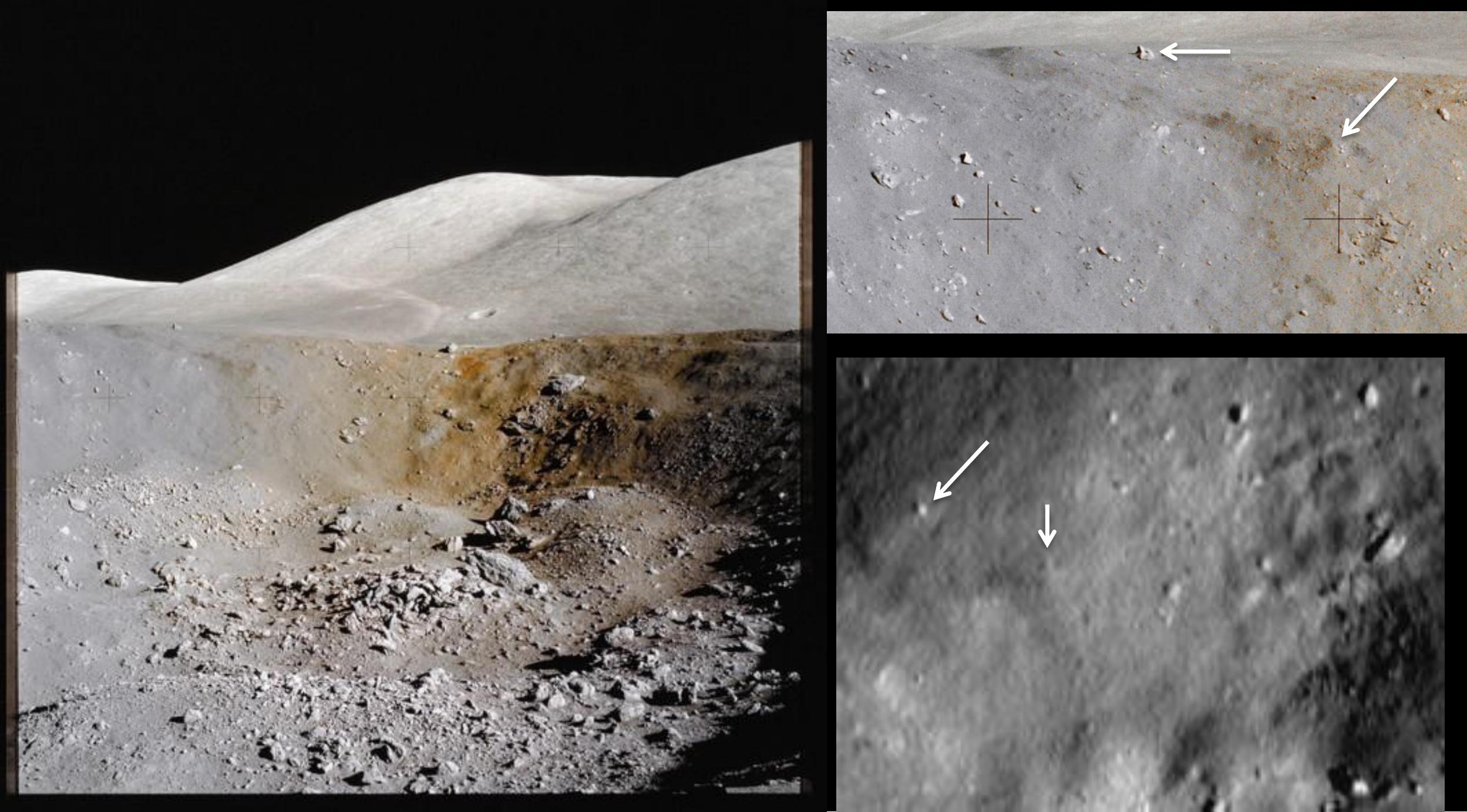


\section{Slide \#29:}

In AS17-137-21001 let's concentrate first on the long black ash streak at the left of the crater wall. Its enlargement is shown at right. The wall slope there must be about the angle of repose, which is $26^{\circ}$ on the Moon, because some of the ash appears to have slipped downwards a bit. The $2^{\text {nd }}$ photo below right is part of the LRO overhead of Shorty and the arrows point to the boulder on the rim, as indicated in the photo above, and to $\mathbf{2}$ small craters at the point where the ash deposit turns down into the crater. (derivative color photos copyright (C) 2018 by Tranquillity Enterprises, s.p.) 


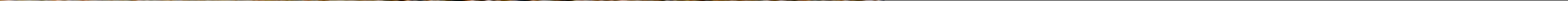




\section{Slide \#31:}

This is an enlargement from the middle of the previous photo, AS17-137-21001. It shows two red splotches just below that big boulder on the rim, and a group of black ash splotches below and to the right of them. At right is the overhead of Shorty to see these same features. The vertical arrows point to the rim boulder. And the horizontal arrows point to the two rocks below the rim boulder. Above and right of the latter are the two red splotches, one darker than the other. (left derivative photo copyright (C) 2018 by Tranquillity Enterprises, s.p.) 


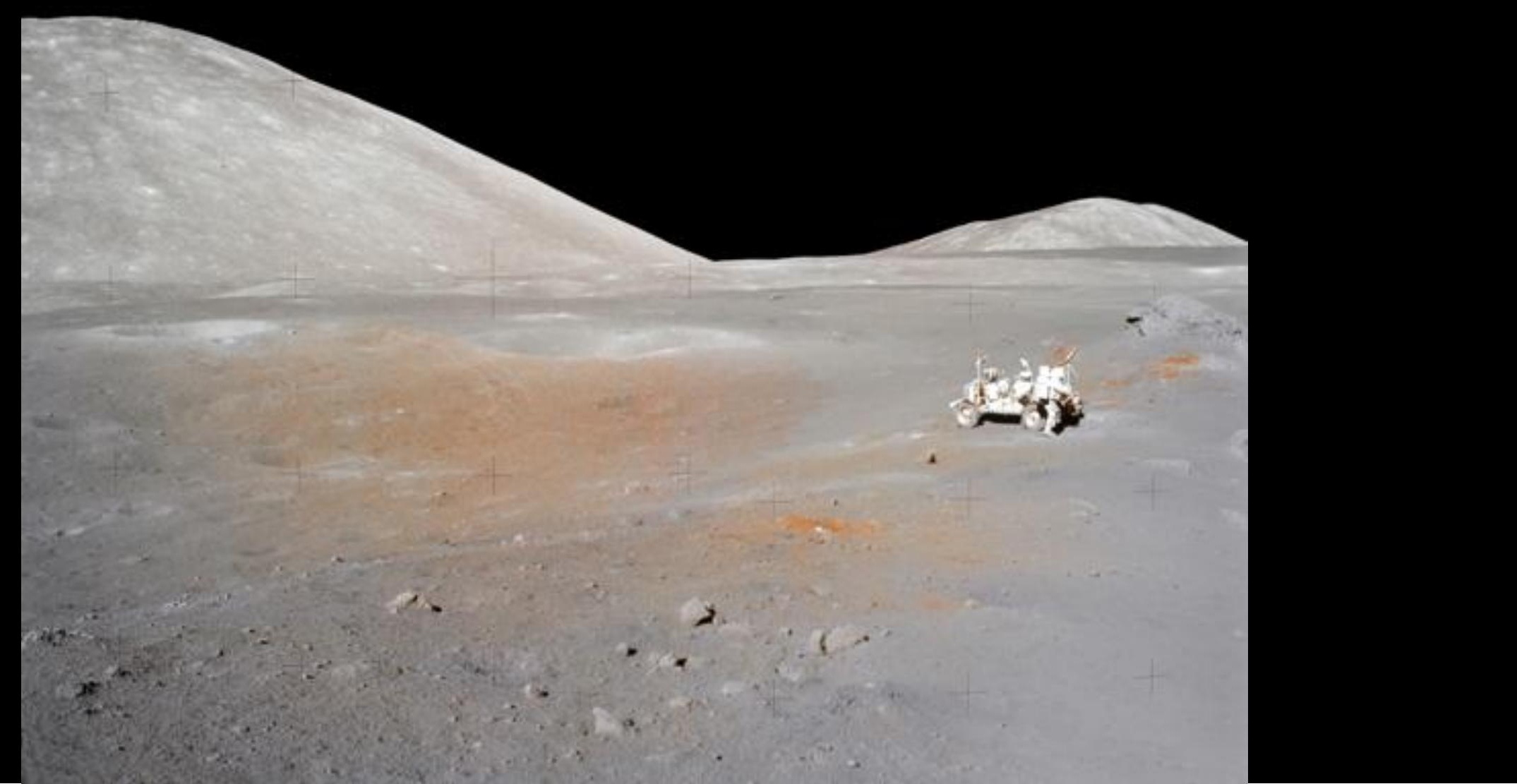




\section{Slide \#33:}

Gene's pans also included Jack at the rover and some of the ejecta blanket beyond Shorty's rim. AS17-137-21012 and 137-21013 are combined here. Jack has the double core tube and is returning to get a sample from the trench seen at the right edge of the photo. Also note another red streak on this side of the rover near those rocks in the foreground, as well as a fairly large, but faint, orange area out on the ejecta blanket. On a higher resolution photo, you can see the rover tracks coming from between those two largish craters in the middle of the photo. (derivative photo copyright (C) 2018 by Tranquillity Enterprises, s.p.). 


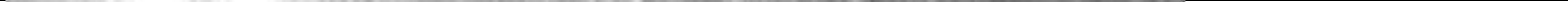




\section{Slide \#35:}

The southern flank of Shorty Crater \& ejecta blanket. The right vertical arrow marks the spot where Cernan made the panoramas. The middle vertical arrow points to the 2 nd red streak area near the $\mathbf{2}$ small boulders. The left horizontal arrow marks the trench. And the uppermost arrow marks the position of the red wall streak. The blue dashed line from between the 2 large craters at left marks the approximate position of the rover tracks. And the dashed orange lines delineate the approximate area of the orangish volcanic ash deposit on the ejecta blanket. One other photo shows a fainter, orangish area on the ejecta blanket off the slide at the lower right: 


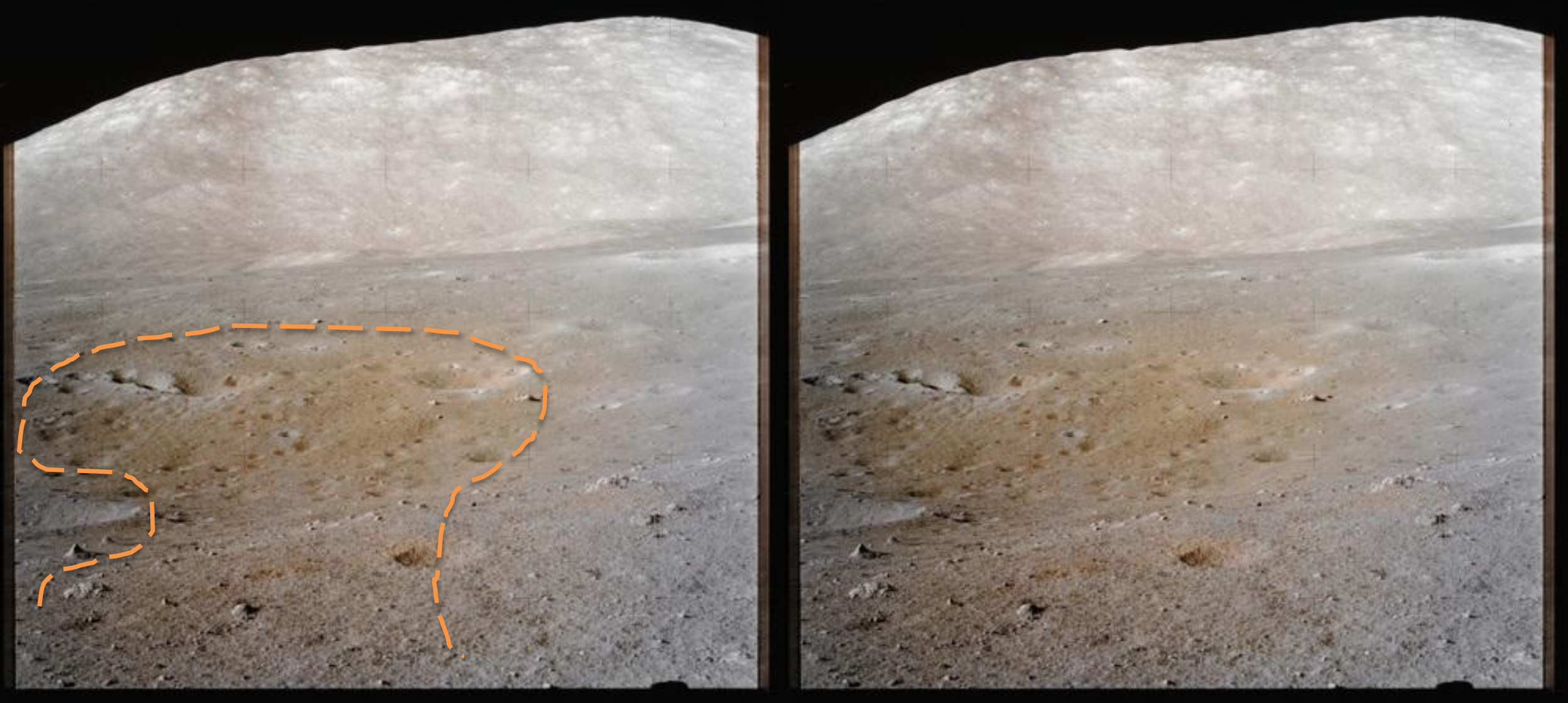




\section{Slide \#37:}

AS17-137-21015. Looking south from Cernan's position. Orange dashed lines approximately outline a 2nd orangish area on the ejecta blanket. $C f$. right panel. The group of overlapping craters at middle left is quite obvious in the LRO overhead, next slide. (derivative photos copyright (C) 2018 by Tranquillity Enterprises, s.p.). 


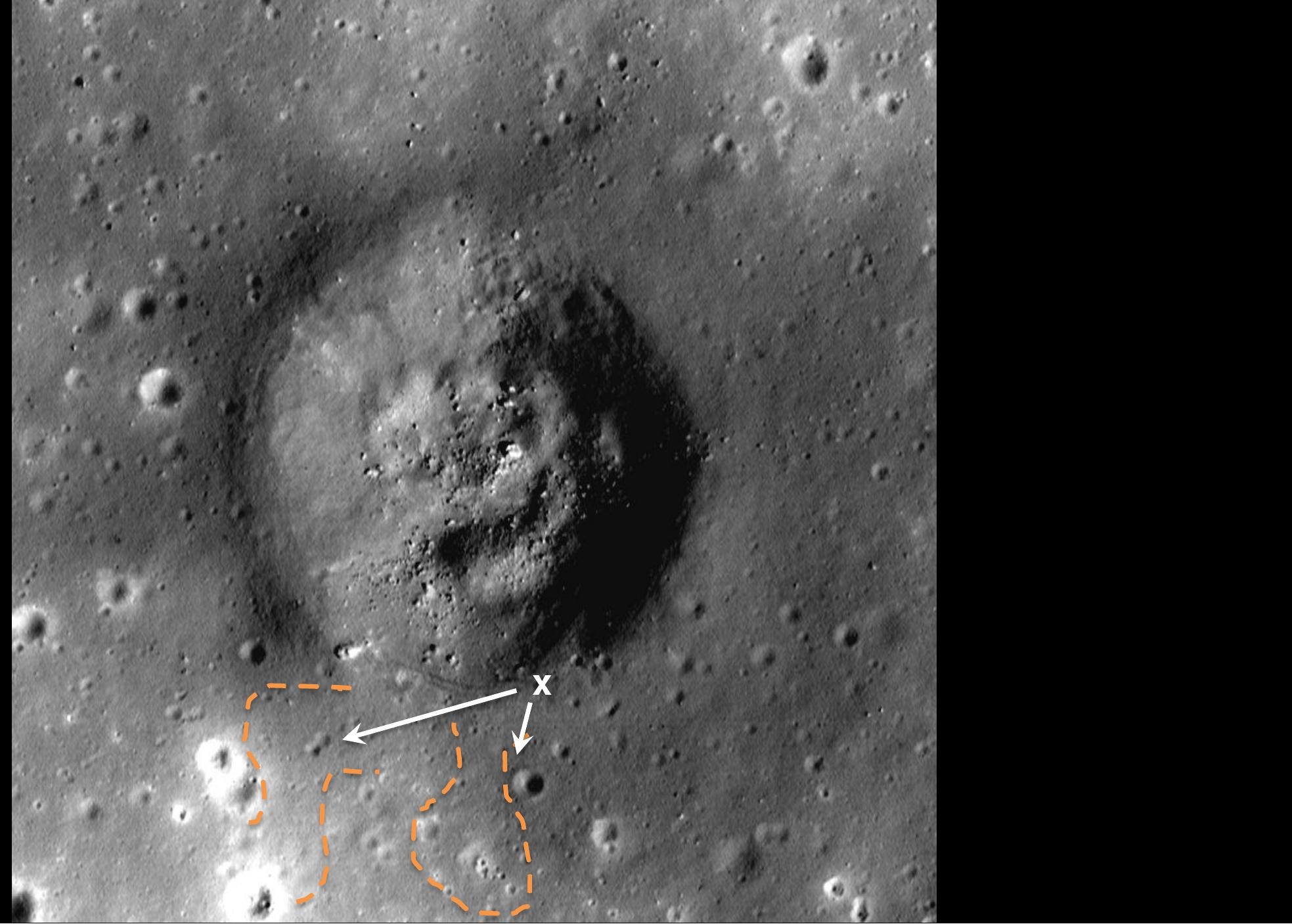




\section{Slide \#39:}

The southwest orange area on the ejecta blanket vs. the south orange area. Note the group of overlapping craters at middle bottom mentioned in previous slide. ' $x$ ' marks Cernan's location. 


\section{Slide \#41:}

This panorama is a composite of AS15-90-12221, 90-12222, and 90-12202 from Irwin's Pan D11. The green soil sampling area is $\mathbf{1 5} \mathbf{m}$ north and east of the big boulder near the middle of the photo on the inner rim of Spur Crater. It is denoted by the large arrow at right. The smaller vertical arrow marks the position of the so-called "Genesis Rock". 


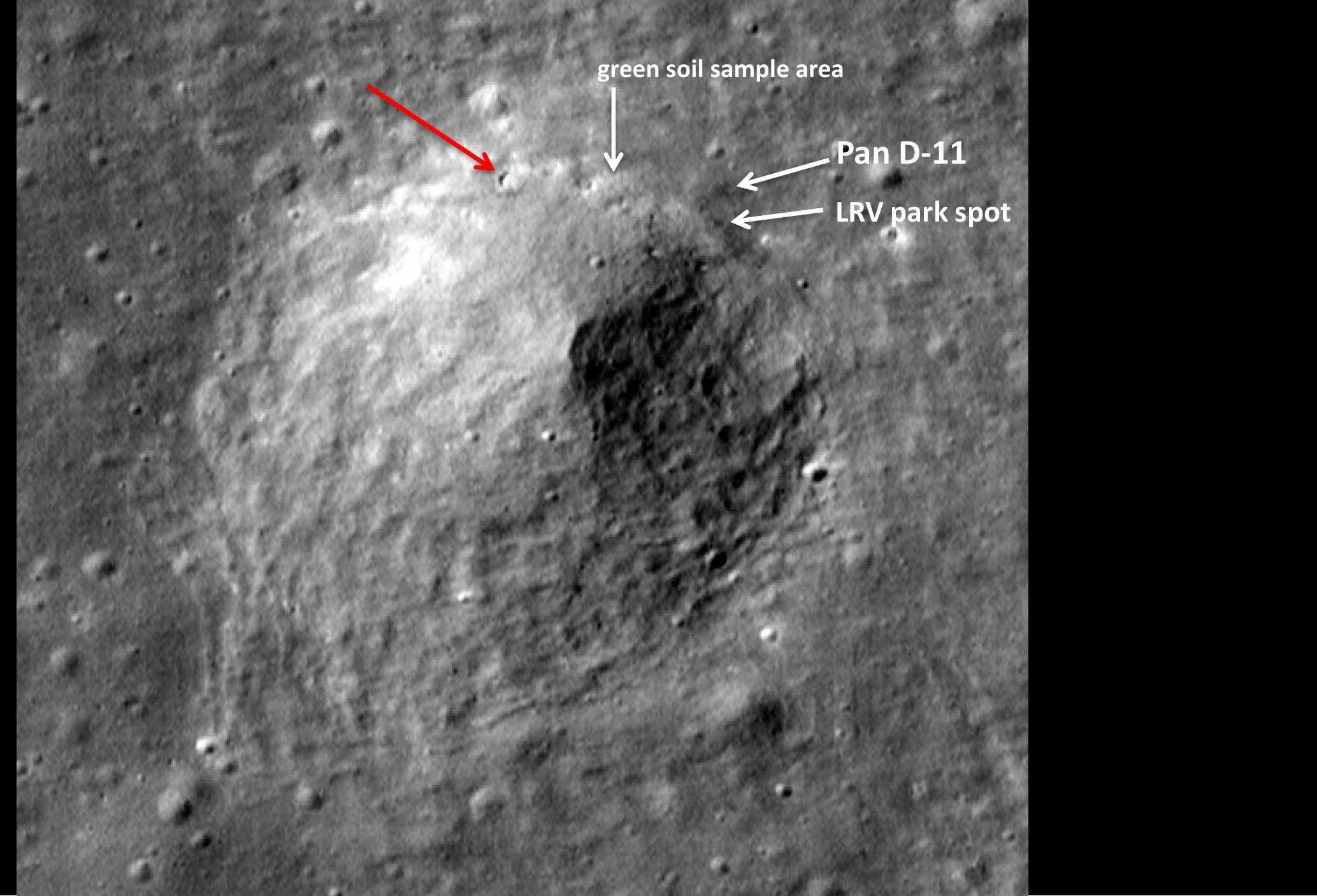




\section{Slide \#43:}

An overhead view of Spur Crater at $28 \mathrm{~cm} / \mathrm{px}$ resolution. Red arrow marks the large rim boulder. The vertical arrow denotes the green soil sampling area. The site of Irwin's Pan D-11 is marked at right and the rover parking spot is just below that. 

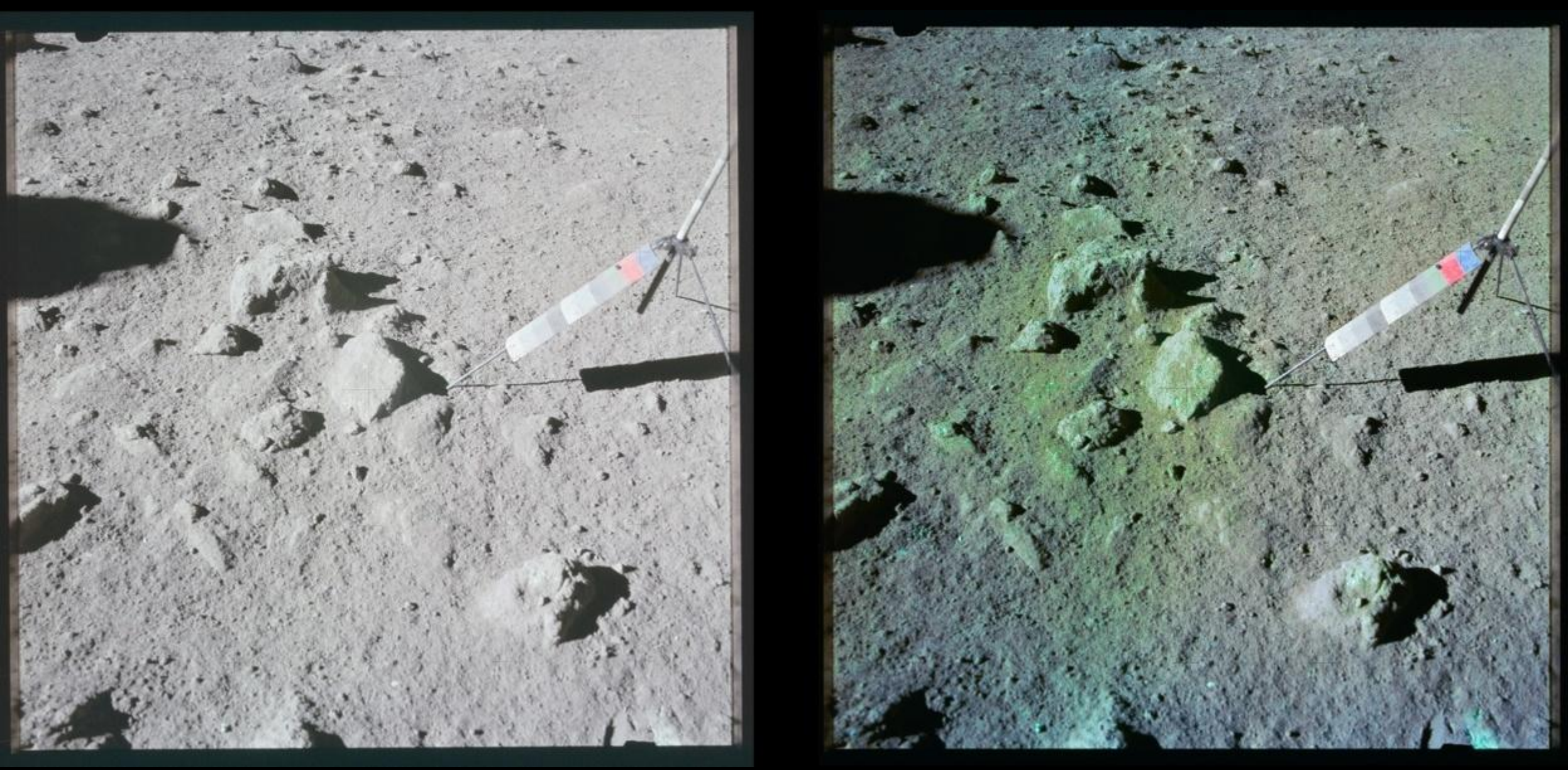


\section{Slide \#45:}

The original JSC scan of the prime film, AS15-86-11666, is at left. The color corrected version is at right, showing the dispersion of green volcanic ash. There are only 4 photos of this sampling area that were made. The digital scanning of all of them are like that at the left: somewhat overexposed, and showing no green color, except on the gnomon chip. However, Irwin said the soil was green looking and the photomicrograph of the soil adhering to rock sample 15426 shows green glass spheroids and shards. (right derivative photo copyright (C 2018 by Tranquillity Enterprises, s.p.) 


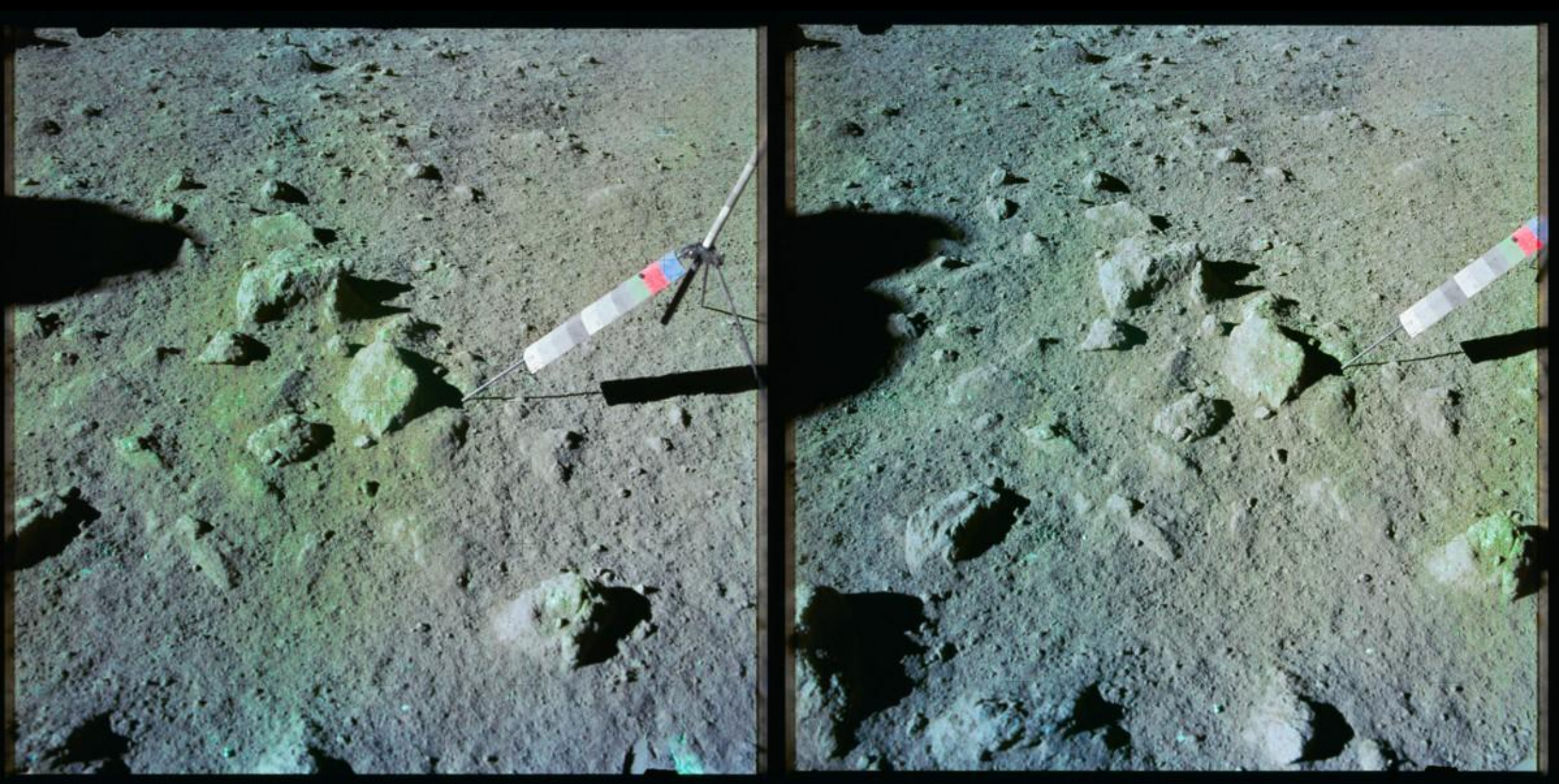




\section{Slide \#47:}

Let's begin again with AS15-86-11666 at left since it forms a stereo pair with AS15-86-11667 at right taken before sample 15426 was removed. (derivative photos copyright (C) 2018 by Tranquillity Enterprises, s.p.) 


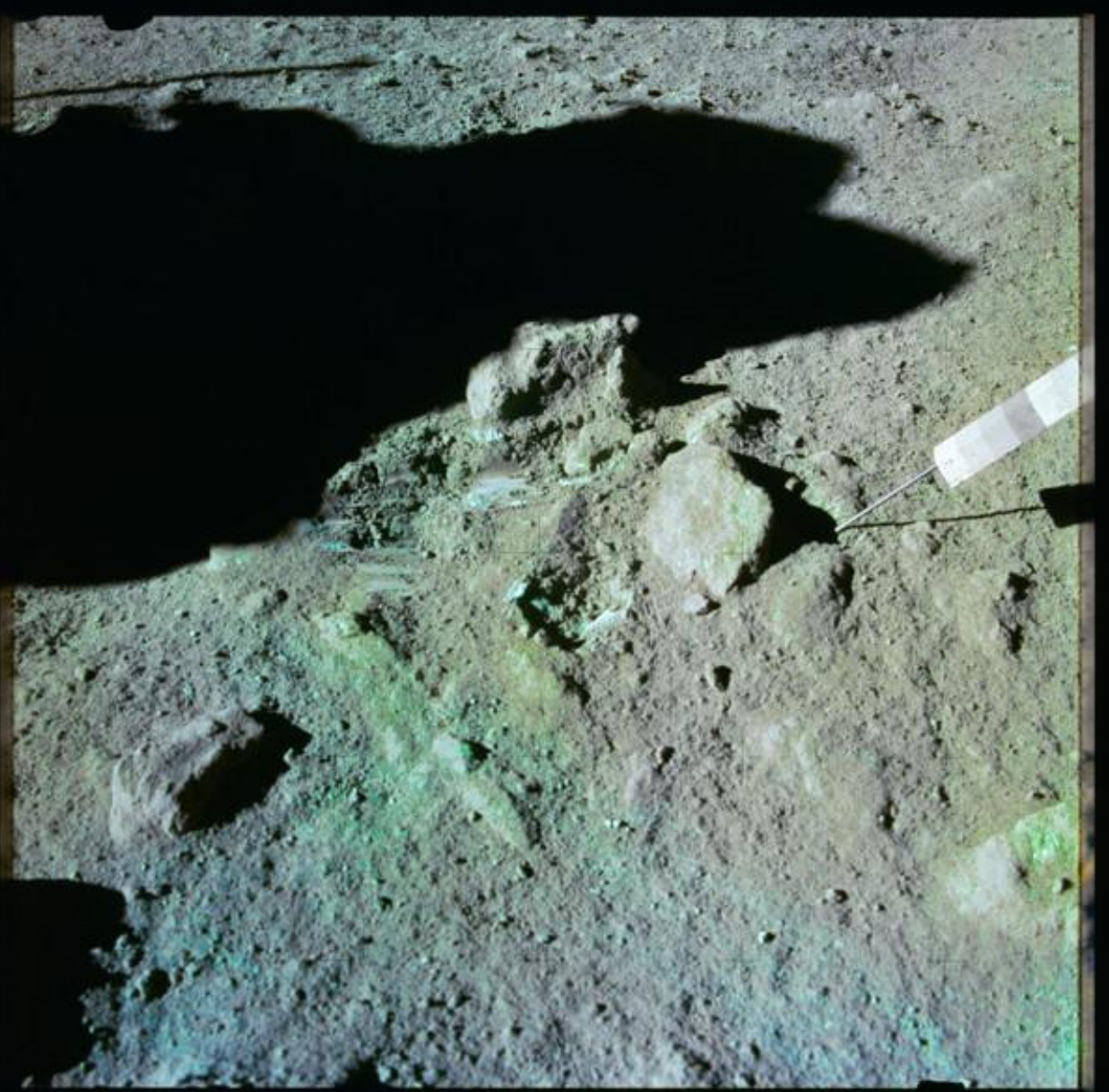




\section{Slide \#49:}

AS15-86-11668 is an "after removal" of the sample, and you can see the cavity where it was situated. AS15-86-11669 is the right photo. Note the spots of green in the interior of the cavity; and in the left photo the green in the boot treads at the bottom, and smaller tread in the middle right photo which shows up as a green-gray-green striped area. (derivative photos copyright (C) 2018 by Tranquillity Enterprises, s.p.) 


\section{Slide \#51:}

Photomicrograph of the green soil adhering to sample 15426, which was seen in situ in the previous slides. The color contrast has been balanced in Adobe Lightroom because NASA released two photomicrographs at the time: one showed deep blue objects, and the other light green ones.

I would just like to conclude with the final sentence in the abstract: "The orange and green lunar volcanic ashes have profound implications related to the geochemical and geophysical nature of the Moon's interior, to the origin of water-ice present at the lunar poles, and to the origin of the Moon" itself. (NASA photo AS15-S79-32188, color corrected). 
E N D 


\section{ENDNOTE:}

Software programs used in the production of the color-balanced photos were Adobe Photoshop, Adobe Lightroom, and Corel Photo-Paint. Since these images are derivative works, they have been registered with the U.S. Copyright Office, registration i.d. = 1-7009355371.

"Fair use" of the images in non-profit web articles, blogs or other electronic documents is permitted provided the photos carry a caption which includes: (Copyright $(02018$ by Tranquillity Enterprises, s.p. Courtesy of Tranquillity Enterprises, s.p.). However, use in printed documents and for-profit publications of any kind is restricted, and requests for their use and/or higher resolution copies in such cases should be directed to the first author of this presentation. 